\title{
A JUDICIALIZAÇÃO PELA DISPPENSAÇÃO DE MEDICAMENTOS E A JURISPRUDÊNCIA DO SUPREMO TRIBUNAL FEDERAL
}

\section{THE JUDICIALIZATION FOR THE DISPENSING OF MEDICINES AND THE JURISPRUDENCE OF THE SUPREME FEDERAL COURT}

\author{
VERSALHES ENOS NUNES FERREIRA ${ }^{1}$ \\ HOMERO LAMARÃO NETO ${ }^{2}$ \\ ELIANA MARIA DE SOUZA FRANCO TEIXEIRA ${ }^{3}$
}

RESUMO: Texto que analisa o atual entendimento do Supremo Tribunal Federal quanto à temática da judicialização da saúde, especificamente quanto ao fornecimento de medicamentos, adotando como marcadores de pesquisa os Recursos Extraordinários 855.178 (tema 793), 657.718 (tema 500) e 566.471 (tema 06), afetados pela sistemática da Repercussão Geral e que, através de seus julgamentos meritórios, fixaram balizas para solução desses litígios. Utiliza a técnica da pesquisa bibliográfica, documental e exploratória, realizando análise qualitativa e aplicando o método dedutivo, para o entendimento e a interpretação das premissas fixadas pela Suprema Corte, buscando responder ao problema de pesquisa concernente em saber se o sistema interpretativo adotado nesses julgamentos propicia maior racionalização às soluções dessas contendas. $\mathrm{O}$ ensaio está estruturado em quatro itens. A introdução será o primeiro; o segundo, explora a judicialização e conceitos correlatos para auxiliar em sua exata compreensão; no subsequente, faz uma análise das teses proferidas e suas consequências para a resolução dessas demandas; por fim, conclui-se que, com o estabelecimento de parâmetros interpretativos vinculantes, a resposta à judicialização alcançará maior segurança jurídica, na medida em que orientada por critérios e limites específicos.

\footnotetext{
${ }^{1}$ Mestre em Direito, Políticas Públicas e Desenvolvimento Regional pelo Centro Universitário do Estado do Pará (CESUPA). Contato: vfenos@gmail.com.

2 Professor do Programa de Pós-Graduação em Direito do Centro Universitário do Estado do Pará (CESUPA). Contato: homerolamaraoneto@yahoo.com.br.

${ }^{3}$ Professora do Programa de Mestrado em Gestão Pública do NAEA - UFPA. Professora da Graduação da Faculdade de Direito do Instituto de Ciências Jurídicas da UFPA. Contato: eliana.f.t@hotmail.com.
} 
Palavras-chave: Judicialização da saúde; Fornecimento de medicamentos; Supremo Tribunal Federal; Fixação de teses em Repercussão Geral; Segurança jurídica.

ABSTRACT: This text analyzes the current understanding of the Federal Supreme Court regarding the issue of health judicialization, specifically regarding the supply of medications, adopting as research markers the Extraordinary Appeals 855.178 (theme 793), 657.718 (theme 500) and 566.471 (theme 06), affected by the General Repercussion system and which, through their meritorious judgments, have set the milestones for the resolution of these disputes. It uses the technique of bibliographic, documentary and exploratory research, performing a qualitative analysis and applying the deductive method to understand and interpret the premises established by the Supreme Court, seeking to answer the research problem of whether the interpretive system adopted in these judgments provides greater rationalization of the solutions to these disputes. The trial is structured in four items. The introduction will be the first; the second, explores judicial review and related concepts to help in their exact understanding; in the subsequent, it makes an analysis of the theses rendered and their consequences for the resolution of these claims; finally, it concludes that, with the establishment of binding interpretative parameters, the response to judicial review will achieve greater legal security, to the extent that it is guided by specific criteria and limits.

Keywords: Judicialization of health; Supply of medicines; Federal Supreme Court; Fixation of thesis in General Repercussion; Legal security.

\section{INTRODUÇÃO}

Estudo elaborado pelo Instituto de Ensino e Pesquisa (INSPER, 2019) para o Conselho Nacional de Justiça (CNJ), divulgado em março de 2019, intitulado "Judicialização da Saúde no Brasil: Perfil das demandas, causas e propostas de solução", demonstrou que entre 2008 e 2017, o número de demandas judiciais relativas à saúde registrou um aumento de $130 \%$.

Os processos de $1^{\text {a }}$ instância, distribuídos entre 17 (dezessete) tribunais de justiça estaduais, passaram de 41.453 em 2008 para 95.752 em 2017, mostrando que o setor de saúde foi responsável por 498.715 processos durante este interregno temporal. Ademais, os processos de $2^{\underline{a}}$ instância, distribuídos entre 15 (quinze) tribunais de justiça estaduais, passaram de 2.969 em 2008 para 40.658 em 2017, totalizando, durante este período, o somatório de 277.411 processos (INSPER, 2019).

Outrossim, os custos da judicialização para o governo federal aumentaram durante o lapso entre 2010 a 2016, passando de pouco mais de R\$ 122 milhões para cerca de R\$ 1.6 bilhão, significando um aumento de mais de 13 (treze) vezes 
no consumo de verbas do SUS (INSPER, 2019). Os medicamentos ainda são a intervenção terapêutica mais utilizada no Brasil (BRASIL, 2020a), sendo o seu acesso um dos eixos norteadores das políticas de medicamentos e de assistência farmacêutica adotadas pelo Sistema Único de Saúde (SUS), tanto que, Braga (2017) acentua que a judicialização pelo fornecimento de fármacos se transformou no principal pleito do cidadão em face do Estado, especificamente quanto ao sistema público de saúde.

Por sua vez, o Relatório Justiça em Números de 2019 (BRASIL, 2019), com dados de 2018, divulgado pelo CNJ, revela a seguinte situação: durante o ano de 2018, englobando, cumulativamente, o $1^{\underline{0}}$ grau, o $2^{\underline{o}}$ grau, os Juizados Especiais, o Superior Tribunal de Justiça, as Turmas Recursais e as Turmas Regionais de Uniformização, alcança-se um total de 1.778,269 demandas de saúde, sendo que, dessas, 544.378 pleiteavam medicamentos já constantes em políticas públicas do SUS. Tais dados denotam que a judicialização se consolidou em nosso país e, por isso, precisa ser discutida, tecnicamente, para que medidas sejam adotadas visando alcançar critérios racionais para sua resolução.

O CNJ, visando colaborar no enfrentamento e solução desses conflitos, editou algumas Resoluções (BRASIL, 2020f), como a 107 de 2010, onde instituiu o Fórum Nacional do Judiciário para a Saúde, responsável pela monitoração e resolução das demandas de assistência à saúde, objetivando reduzir a judicialização, sem limitações ao acesso à Justiça, e a 238 de 2016, regulamentando os Comitês Estaduais de Saúde, compostos por múltiplas instituições e marcados pelo debate científico e diálogo na prevenção e contribuição para dirimir, sem litígio, as questões envolvendo prestações de saúde, nas searas pública e privada.

Ao lado dessas Resoluções, merece destaque a Recomendação nº 31/2010, que trouxe orientações para auxiliar os juízes nas decisões relativas à prestação de serviços de saúde, assim como, o efetivo trabalho desempenhado pelo Fórum Nacional de Saúde (instituído pela Resolução n⿳0 107/2010 - CNJ), que já produziu resultados importantes como as Jornadas de Direito da Saúde e seus Enunciados ${ }^{4}$, que servem ao propósito de fixar linhas interpretativas sobre o direito à saúde, orientando as manifestações judiciais acerca da matéria.

Muito embora o CNJ venha desenvolvendo ferramentas e traçando parâmetros mais seguros e eficazes para o enfrentamento da judicialização, a questão é que esta é uma realidade assente em nosso país, cujo aumento é perceptível, seja no número de demandas, seja no quantum financeiro necessário para cumprir as determinações judiciais. Inclusive, cabe um alerta, porque a judicialização não trata de uma coisa só, sabe-se que existe uma sensível diferença

\footnotetext{
${ }^{4}$ Os Enunciados das Jornadas de Direito da Saúde estão disponíveis, na íntegra, no seguinte endereço:

https://www.cnj.jus.br/wpcontent/uploads/2019/03/e8661c101b2d80ec95593d03dc1f1d3e.pdf.
} 
entre pleitear um medicamento da RENAME (já incorporado pelo SUS) e um fármaco de alto custo fora de nossas políticas públicas; no primeiro caso, não podemos falar de incrementos financeiros em tese, na medida em que as demandas versam sobre o que já é garantido pelo SUS, diferente do segundo caso, quando pode vir a existir a necessidade de incremento financeiro, notadamente quando há bloqueio de verbas ou multas para o ente federativo cumprir a determinação judicial.

A evolução exponencial dessas ações, desdobramento, pode-se dizer, de uma maior conscientização de direitos por parte dos cidadãos, resultando em uma maior cobrança dos entes estatais, bem como, de uma constante falta de recursos e de gestão competente, que acabam repercutindo em um crônico subfinanciamento, aliado aos desvios decorrentes da corrupção, são fatores que impedem uma ampliação e otimização da distribuição das políticas públicas de saúde.

Evidentemente, o crescimento dos pedidos de medicamentos, tratamentos e insumos, incorporados ou não pelo SUS ${ }^{5}$, e a irresignação dos entes públicos, nos diversos níveis da Federação, resulta na interposição de instrumentos recursais que, acabam desembocando no Supremo Tribunal Federal (STF) e, perante a Corte, diante da Sistemática da Repercussão Geral, alguns Recursos Extraordinários foram escolhidos como paradigmáticos para a discussão em torno da matéria concernente ao fornecimento de medicamentos pelo Estado, reputando-se constitucional as questões suscitadas, foram eles: RE 566.471 (tema $06^{6}$ ), RE 657.718 (tema 5007) e RE 855.178 (tema $793^{8}$ ).

Neste ensaio, pretendemos analisar os entendimentos fixados pelo STF por ocasião do julgamento dos Recursos Extraordinários retro mencionados, explorando seus desdobramentos fáticos para o fenômeno da judicialização da saúde, não olvidando que as decisões proferidas pelo Plenário da Suprema Corte no julgamento de Recurso Extraordinário com Repercussão Geral vinculam os demais órgãos do Poder Judiciário na solução, por estes, de outros litígios sobre idêntica controvérsia.

Quanto à metodologia, o ensaio utiliza as técnicas da pesquisa bibliográfica, documental e exploratória, realizando análise qualitativa e aplicando o método dedutivo, para o entendimento e a interpretação das premissas fixadas pelo

\footnotetext{
${ }_{5}^{5}$ Para este estudo, a abordagem ficará restrita, exclusivamente, ao campo da saúde pública, implementada através do SUS, sendo de responsabilidade de todos os entes da Federação e financiado com recursos do orçamento da seguridade social, da União, dos Estados, do Distrito Federal e dos Municípios, além de outras fontes de custeio.

${ }^{6}$ Tema 6 - Dever do Estado de fornecer medicamento de alto custo a portador de doença grave que não possui condições financeiras para comprá-lo.

${ }^{7}$ Tema 500 - Dever do Estado de fornecer medicamento não registrado pela ANVISA.

${ }^{8}$ Tema 793 - Responsabilidade solidária dos entes federados pelo dever de prestar assistência à saúde.
} 
Supremo Tribunal Federal, visando compreender a realidade após o delineamento dessas vinculações e objetivando responder ao problema de pesquisa concernente em saber se o sistema interpretativo adotado pela Corte ofertará maior racionalização às soluções judiciais conferidas a essas contendas, assegurando a integridade do direito à saúde.

Estruturalmente, o texto está dividido em quatro itens. A introdução será o primeiro; o segundo, explora a judicialização e conceitos básicos para sua escorreita compreensão; o terceiro, realiza uma análise das teses fixadas, lançando luzes sobre o sistema interpretativo delineado e suas consequências para a resolução das demandas referentes à dispensação de medicamentos; por fim, conclui-se que, com o estabelecimento de parâmetros interpretativos vinculantes, a resposta à judicialização alcançará maior segurança jurídica e racionalização, posto que orientada por critérios e limites específicos.

\section{JUDICIALIZAÇÃO DO DIREITO À SAÚDE: CONCEITOS BÁSICOS}

A positivação de direitos no corpo de uma Constituição e a elevação, com isso, do caráter imperativo dessas normas, naturalmente trazem consequências para a sociedade e para o mundo jurídico. A importância das políticas públicas ganha relevo, na medida em que se tornam os instrumentos administrativos hábeis para dar concretude, efetivação aos bens jurídicos elencados como fundamentais pelo legislador constituinte originário. Por outro lado, esses programas de ação governamental não conseguem atender a todos, e não conseguem dar conta de todos os interesses primordiais da sociedade, notadamente porque esta é complexa e plural, acolhendo uma diversidade de concepções individuais sobre vida digna.

O resultado prático desse descompasso entre o que a Constituição da República Federativa do Brasil de 1988 (CRFB/88) elencou como essencial para o indivíduo singularmente considerado e o que as políticas públicas conseguem realizar efetivamente, causa situação de desrespeito ao texto constitucional e deixa o cidadão sem acesso ao direito considerado fundamental para sua vida. No caso da saúde, a CRFB/88 elegeu a universalidade como vetor primacial deste bem, seja quando previu o atendimento integral e proteção contra o risco de doença e de outros agravos, seja quando declinou que era um direito de todos e dever do Estado, independentemente da classe social e de qualquer contraprestação financeira.

Deste modo, quando o pleito do cidadão não é satisfeito pelo Poder Público, em outras palavras, quando suas necessidades sociais não são satisfeitas pelo Estado, a alternativa é demandar os entes federativos ligados ao SUS, quando caberá ao Poder Judiciário a tarefa de interpretar e buscar dar a máxima efetividade àquela determinada categoria de direitos, assegurando o acesso à prestação positiva do direito fundamental. Nesse ínterim, nasce a ideia de 
judicialização, pautada no deslocamento de decisões políticas que estão, originariamente, no contexto de atuação de Executivo e Legislativo, para o âmbito do Poder Judiciário, a quem caberá dirimir as situações que estão gerando conflitos. Cumpre frisar, em adendo, que a menção ao Poder Legislativo advém do fato de que cabe a este a criação da norma que pode ampliar a distribuição das políticas públicas de saúde.

A judicialização do direito à saúde caminha dentro dessa conjuntura, no aspecto em que o Poder Público adquiriu novas obrigações jurídicas para com seus cidadãos e, por diversas motivações como inoperâncias, subfinanciamento, gestão ineficiente, os gestores não conseguem integralizar a distribuição do direito assegurado pela CRFB/88, apesar de que, e é bom frisar, o SUS é gigante e operante, funcionando como a única porta aberta no campo da saúde, em que pesem os desafios que precisam ser superados. Frise-se que, nas demandas em que se pleiteiam fármacos já constantes em políticas públicas do SUS, não há deslocamento de decisão política para o Judiciário, este apenas garante o que o legislador já o fez.

Ainda que se alegue que muitos dos pedidos realizados pelas pessoas não estão no rol de tecnologias ${ }^{9}$ que são dispensadas pelo SUS, também é verdade que tantas outras demandas buscam, exatamente, o que já faz parte da política pública e, por isso, não deveriam ser objeto de judicialização, na medida em que fazem parte daquilo que o próprio SUS se obrigou a distribuir, e, assim, deveriam estar à disposição dos cidadãos.

Observe-se que a judicialização é um fenômeno contemporâneo e, considerando o crescente número de ações versando sobre pedidos de tecnologias para o SUS, a definição de balizas vinculantes exsurge como questão que deve ser enfrentada pela Suprema Corte. Até porque a efetivação judicial de direitos prestacionais deve obedecer a orientações muito específicas, capazes de, a um só tempo, proteger o direito individual à saúde do cidadão, sem descurar das políticas públicas direcionadas para a coletividade, conquanto que estas são, previamente, fixadas no orçamento público. As ações individuais visando dispensação de fármacos não incorporados nas políticas públicas do SUS, quando deferidas judicialmente, exigem que recursos sejam manejados do quantum outrora estipulado para custear as ações e serviços então delimitados.

\footnotetext{
${ }^{9}$ Segundo o Ministério da Saúde (BRASIL, 2016), tecnologia em saúde se refere à aplicação de conhecimentos com objetivo de promover a saúde, prevenir e tratar as doenças e reabilitar as pessoas. São exemplos de tecnologias em saúde: medicamentos, produtos para a saúde, procedimentos, sistemas organizacionais, educacionais, de informação e de suporte e os programas e protocolos assistenciais por meio dos quais a atenção e os cuidados com a saúde são prestados à população. A utilização correta dessas tecnologias em saúde e a atualização constante das informações sobre elas são imprescindíveis para um maior benefício para os pacientes, cuidadores e familiares.
} 
Convém frisar, para que não restem dúvidas, que se defende que todo cidadão pode e deve ajuizar demandas em face do Estado, pleiteando medicamentos, insumos e tratamentos, sendo que a pretensa titularidade universal advinda da fundamentalidade deste direito, conquanto ligado à dignidade humana e à vida, decorre da própria Constituição e da condição de ser a saúde um bem essencial à vida humana ${ }^{10}$. A perda de qualquer vida deve sempre ser lamentada, e se existe meio para salvá-la, então, o acesso à Justiça deve ser exercitado. Todos os seres humanos têm igual valor, e a vida é o bem supremo.

Por óbvio, não se está aqui defendendo uma absoluta possibilidade de pleitear todo e qualquer serviço, procedimento ou medicamento, mas apenas o quantum indispensável à preservação de uma vida com dignidade, levando-se em consideração, dentre outros, o critério das evidências científicas. E mais, não é qualquer demanda que se apresenta legítima. A dispensação judicial de medicamentos que já fazem parte das políticas do SUS são, certamente. E, não geram despesas adicionais. As ações que pleiteiam fármacos fora das listas do SUS geram despesas adicionais e, encontram justificativa porque se circunscrevem à ideia de um núcleo de proteção essencial ao indivíduo.

Entrementes, o magistrado não pode mais, isoladamente, decidir sobre a dispensação ou não de fármaco, é necessário aliar seu conhecimento ao dos profissionais que possuem a expertise para analisar sintomas, receitar fármacos, dispor sobre dosagens, avaliar efeitos colaterais e substituir tecnologias ineficazes. A ciência jurídica não é autossuficiente, não é capaz de resolver todas as problemáticas da sociedade, da vida humana, e isso é um fato. É por isso que a importância dos PCDT (Protocolos Clínicos e Diretrizes Terapêuticas) ganha relevância, na medida em que fruto do consenso da medicina e das regras do SUS.

Por oportuno, na esteira da necessidade de demonstrar a imprescindibilidade de se ter conhecimento de como funciona o Sistema de Saúde em relação à questão de fornecimento de medicamentos, o ensaio explicará, nas linhas vindouras, termos e instrumentos utilizados no campo administrativo e que servirão à escorreita compreensão do alcance da judicialização, repercutindo nas decisões judiciais prolatadas ${ }^{11}$. Neste contexto, é relevante assimilar a ideia de:

\footnotetext{
${ }^{10}$ Adota-se a posição, aderindo à doutrina defendida por Sarlet (2015, p. 336-342. 2019, p. 658-659), Brito Filho (2008, p. 139-143), Araujo \& Nunes Júnior (2018, p. 632), Lamarão Neto (2018, p. 96106) e Ferreira (2019, p. 96-116), no sentido de que o direito à saúde apresenta uma titularidade simultaneamente individual e transindividual, permitindo-se, deste modo, uma dedução judicial individual e coletiva de se obter prestações do SUS, considerando que resguardar esse bem jurídico fundamental significa proteger a vida e a dignidade humana.

${ }^{11}$ Neste desiderato, sugere-se consulta à (PARÁ, 2018) que se revela uma importante ferramenta para auxiliar na resolução das demandas por fornecimento de medicamentos no âmbito do SUS, ajudando, inclusive, na avaliação da responsabilidade entre os entes federativos.
} 
I) Medicamentos incorporados e Medicamentos não incorporados pelo SUS e a Agência Nacional de Vigilância Sanitária (ANVISA);

II) Relação Nacional de Medicamentos Essenciais (RENAME) e o Componente Especializado da Assistência Farmacêutica (CEAF);

III) Protocolos Clínicos e Diretrizes Terapêuticas (PCDT) e a Comissão Nacional de Incorporação de Tecnologias no SUS (CONITEC), e;

IV) Medicina Baseada em Evidências (MBE).

Passamos a analisar cada um deles:

I) Medicamentos incorporados e Medicamentos não incorporados pelo SUS e a ANVISA $^{12}$. A primeira grande questão que exsurge no contexto da judicialização do fornecimento de medicamentos é a referente ao fato da tecnologia já estar ou não incorporada pelo SUS. Deste modo, existem duas modalidades principais de judicialização.

Na primeira, temos os medicamentos incorporados ao SUS, isto é, fármacos que estão incluídos na política pública de saúde, devendo ser objeto de dispensação gratuita à população, sendo que, para o recebimento, o cidadão deve estar cadastrado em programas estatais e municipais para recebimento desses medicamentos, salvo para o programa farmácia popular. Aqui, não há dúvida da obrigação do Estado em fornecê-lo. O Judiciário, neste caso específico, tem uma atuação voltada para efetivar as políticas públicas outrora formuladas no âmbito do SUS. O autor da demanda deve provar a necessidade do medicamento e a tentativa frustrada de obtê-lo pela via administrativa ${ }^{13}$. Frise-se que os medicamentos estão presentes, nesta situação, nos Protocolos do SUS e nas listas de dispensação, o que pode ter ocorrido, e deve ser evitado, é falta de planejamento, de licitação etc., enfim, falhas que precisam ser corrigidas. Nesta primeira modalidade, os programas mais usados são a RENAME, a Farmácia popular $^{14}$, além da Política Nacional de Assistência Farmacêutica ${ }^{15}$.

${ }^{12}$ A Agência Nacional de Vigilância Sanitária (on line) é uma autarquia sob regime especial criada pela Lei no 9.782, de 26 de janeiro 1999, estando presente em todo o território nacional por meio das coordenações de portos, aeroportos, fronteiras e recintos alfandegados, e tendo por finalidade institucional promover a proteção da saúde da população, por intermédio do controle sanitário da produção e consumo de produtos e serviços submetidos à vigilância sanitária, inclusive dos ambientes, dos processos, dos insumos e das tecnologias a eles relacionados, bem como o controle de portos, aeroportos, fronteiras e recintos alfandegados.

${ }^{13} \mathrm{O}$ Enunciado 03 das Jornadas de Direito da Saúde afirma: “Nas ações envolvendo pretensões concessivas de serviços assistenciais de saúde, o interesse de agir somente se qualifica mediante comprovação da prévia negativa ou indisponibilidade da prestação no âmbito do Sistema Único de Saúde - SUS e na Saúde Suplementar".

${ }^{14}$ A Farmácia Popular é uma alternativa de acesso a medicamentos e insumos destinados a tratamentos de agravos com maior incidência na população, a União implementou o Programa Farmácia Popular do Brasil - PFPB que está disponível na rede privada de farmácia e drogarias conveniadas ao programa por meio da adesão ao PFPB "Aqui tem Farmácia Popular", conforme estabelece a Portaria de Consolidação n. 5, de 28 de setembro de 2017 (art. 572, 573 e anexos 
A segunda modalidade diz respeito aos medicamentos não incorporados pelo SUS. Aqui, o Estado não é, como regra, obrigado a fornecê-lo, principalmente quando se está diante de fármacos de alto custo. Em outras palravas, o Poder Público não é obrigado a dispensar medicamentos fora de suas políticas públicas. Aqui, não se tem dispensação gratuita, na medida em que o medicamento não está incluído nas listas do SUS, a exemplo da RENAME. Nesta situação, a prestação pleiteada é diversa da oferecida pelo sistema público, seja porque o SUS adotou outra levando em conta a relação custo $x$ benefício, sendo o critério legalmente estabelecido pela norma especializada, ou porque ainda não incorporou aquela desejada aos protocolos e diretrizes terapêuticos por não existirem evidências clínicas de sua eficácia.

$\mathrm{Na}$ conjuntura da judicialização, o jurisdicionado busca medicamentos registrados (na ANVISA) e não incorporados às políticas do SUS (não constam da lista), outros buscam aqueles que nem registro na ANVISA possuem. E, o registro perante a autoridade sanitária, cumpre ressaltar, é essencial para que o produto seja analisado pela CONITEC, conforme determina o artigo 19-Q, $\$ 2^{2}$, inciso I da Lei $\mathrm{n}^{\mathrm{o}}$ 8.080/1990. Em termos simplórios, o SUS só incorpora medicamentos em suas políticas públicas se ele tiver sido registrado pela ANVISA.

A Lei no 6.360, de 23 de setembro de 1976, determina em seu artigo 12 que medicamentos, insumos farmacêuticos e correlatos, inclusive os importados, não poderão ser industrializados, expostos à venda ou entregues ao consumo antes de serem registrados no Ministério da Saúde, cabendo à ANVISA fazê-lo. O registro de tecnologia na referida agência reafirma os critérios de segurança e eficácia, demonstrando a existência de comprovados resultados científicos para o tratamento de uma determinada patologia. $\mathrm{O}$ controle sanitário de fármacos nacionais e importados, realizado pela ANVISA, garante sua qualidade.

LXXVII e LXXVIII). Através do programa, os medicamentos relacionados para hipertensão, diabetes e asma são dispensados de maneira gratuita, sendo os demais dispensados com desconto de até $90 \%$ (PARÁ, 2018, p. 16).

${ }^{15}$ A Política Nacional de Assistência Farmacêutica foi aprovada pela Resolução no 338, de 06 de maio de 2004 do Conselho Nacional de Saúde, nascendo como parte integrante da Política Nacional de Saúde, envolvendo um conjunto de ações voltadas à promoção, proteção e recuperação da saúde e garantindo os princípios da universalidade, integralidade e equidade. Dentro deste contexto, a Assistência Farmacêutica deve ser compreendida como política pública que trata de um conjunto de ações voltadas à promoção, proteção e recuperação da saúde, tanto individual como coletivo, tendo o medicamento como insumo essencial e visando o acesso e ao seu uso racional. Em termos simplórios, exsurge como a área do SUS responsável por garantir à população o acesso a medicamentos essenciais, tendo como diretrizes a adoção da RENAME, a regulamentação sanitária dos medicamentos, a garantia da segurança, da eficácia e da efetividade dos fármacos e a promoção do uso racional dos medicamentos, definidas na Política Nacional de Medicamentos, consoante Portaria de Consolidação no 2, de 28 de setembro de 2017 (artigo 6으, VII; item 4.5; Anexo XXVII) (BRASIL, 2004). 
Convém referenciar, por oportuno, que existe hipótese excepcional de dispensa de registro para importação do medicamento pela ANVISA, nos termos da Lei no 9.782/99 (que criou a ANVISA), quando permitiu que ela dispense de "registro" medicamentos adquiridos por intermédio de organismos multilaterais internacionais, para uso de programas em saúde pública pelo Ministério da Saúde (LAMARÃO NETO, 2018). É preciso ressaltar que o registro constitui proteção à saúde pública, na medida em que, repita-se, atesta a eficácia, segurança e qualidade dos fármacos comercializados no país, além de colaborar no controle de preços.

II) Relação Nacional de Medicamentos Essenciais (RENAME) e o Componente Especializado da Assistência Farmacêutica (CEAF) (antigo Programa de Dispensação de Medicamentos em Caráter Excepcional). A política de saúde instituída pela $\mathrm{CRFB} / 88$ compreendeu a dispensação de fármacos aos cidadãos, inclusive aqueles considerados de "alto custo". A assistência farmacêutica está, expressamente, prevista na Lei n⿳0 8.080/1990 (Lei Orgânica da Saúde), conforme artigo 6º inciso I, alínea “d”. Em 2011, a Lei nº 12.401 alterou a Lei Orgânica da Saúde para definir, entre outros, que a assistência terapêutica integral inclui a dispensação de medicamentos cuja prescrição "esteja em conformidade com as diretrizes terapêuticas definidas em protocolo clínico para a doença ou o agravo à saúde a ser tratado" ou, na falta do protocolo, esteja previsto nas relações de medicamentos instituídas pelos gestores federais, estaduais e municipais do SUS (artigos 19-M e 19-P).

A escolha dos medicamentos que serão incorporados pelo SUS - e que, então, poderão compor a RENAME, atualmente regulamentada pelo Decreto $\mathrm{n}^{\circ}$ 7.508/2011 - constitui uma política pública de saúde. Tal política é definida após avaliação dos fármacos quanto à sua eficácia, segurança, efetividade e custoefetividade para as diferentes fases evolutivas da doença ou do agravo à saúde em questão (artigo 19-O, parágrafo único, Lei no 8.080/1990). Atualmente, a incorporação, a exclusão ou a alteração pelo SUS de tecnologia em saúde, bem como, a constituição ou alteração de Protocolos Clínicos e Diretrizes Terapêuticas são atribuições do Ministério da Saúde, assessorado pela CONITEC, criada com a Lei $\mathrm{n}^{\mathrm{o}} 12.401 / 2011$.

Cabe ressaltar que o elevado valor unitário de um medicamento não é impeditivo para sua incorporação pelo SUS para dispensação gratuita. Com o objetivo de garantir acesso integral ao tratamento medicamentoso em relação a todas as formas evolutivas das diferentes doenças, as listas do SUS abrangem, inclusive, fármacos de expressivo custo unitário, sem que isso constitua obstáculo à elaboração da política pública. Aliás, medicamentos de alto custo integram o serviço público de saúde, sobretudo quando constam nas listagens oficiais do SUS, uma vez que ao serem inseridos nessas relações são tidos como elementos da própria política em si, na medida em que são indispensáveis para o restabelecimento da saúde do cidadão. 
Deste modo, cabe à Assistência Farmacêutica a responsabilidade por garantir à população o acesso a medicamentos essenciais, cabendo à RENAME realizar essas indicações, tudo em observância à Política Nacional de Medicamentos (instituída pela Portaria GM/MS no 3.916, de 30/10/1998), alicerçada conforme Portaria de Consolidação no 2, de 28/09/2017. Frise-se que a RENAME comporta três blocos de medicamentos, cada um com padrão de aquisição e distribuição, são eles: componentes básicos, estratégicos e especializados (JORGE, 2017).

O componente básico da assistência farmacêutica é o nível primário de acesso à assistência medicamentosa, garantindo aos cidadãos a oferta de tecnologias essenciais, que são, em linhas gerais, aqueles dispensados pelas unidades da rede de atenção básica municipal de saúde. Seu financiamento é tripartite (União, Estados e Municípios), porém, a execução das ações e serviços de saúde e a aquisição, armazenamento, distribuição e dispensação dos medicamentos e insumos cabe aos Estados, Distrito Federal e Municípios.

O componente especializado da assistência farmacêutica contempla a oferta de medicamentos para doenças que, a despeito de atingir número limitado de pessoas, requerem tratamento longo ou até permanente, com uso de fármacos, em geral, de custos elevados, que por tal motivo não podem, na maioria das vezes, ser adquiridos pelos próprios pacientes. A título de exemplo tem-se moléstias como esclerose múltipla e doença de Parkinson, sendo que o tratamento deve estar alinhado aos PCDT do Ministério da Saúde. Aqui, existe um rateio da responsabilidade entre os entes da Federação, cabendo a incumbência do financiamento ao Ministério da Saúde e às Secretarias do Estado e do Distrito Federal.

Outrossim, temos o componente estratégico da assistência farmacêutica, que é focalizado no financiamento de ações de assistência medicamentosa de doenças endêmicas. Neste bloco, são contemplados programas de saúde estratégicos voltados para o controle de endemias, a exemplo de tuberculose, hanseníase, malária, leishmaniose, doença de Chagas, e de outras doenças endêmicas de abrangência nacional ou regional, como a cólera, filariose, meningite, esquistossomose, e outras doenças decorrentes e perpetuadoras da pobreza, assim como, fármacos para o programa de AIDS e doenças hematológicas. Acrescentouse, também, programas para alimentação e nutrição, controle do tabagismo, saúde da criança e influenza.

Cabe ao Ministério da Saúde a formulação dos protocolos de tratamento, planejamento e programação, financiamento e aquisição centralizada e distribuição aos Estados e/ou Municípios. Por sua vez, o armazenamento, distribuição às regionais ou Municípios e programação é de responsabilidade das Secretarias Estaduais de Saúde. Ao fim, compete às Secretarias Municipais de Saúde o armazenamento, distribuição às unidades de saúde, programação e dispensação. O financiamento dos programas estratégicos cabe à União. 
Por fim, de acordo com a Portaria $n^{0} 3.047$, de 28/11/2019, do Ministério da Saúde, ficou estabelecida a Rename 2020 no âmbito do SUS, atualizando o elenco de medicamentos e insumos a serem dispensados à sociedade. Foram considerados os fármacos incluídos, excluídos e alterados pela CONITEC entre setembro de 2018 a novembro de 2019, e que passaram por pactuação de financiamento na Comissão Intergestores Tripartite. Atualmente, a RENAME comporta 921 (novecentos e vinte e um) itens, entre medicamentos e insumos (BRASIL, 2020b).

Ademais, o Componente Especializado da Assistência Farmacêutica (CEAF), outrora denominado Programa de Dispensação de Medicamentos em Caráter Excepcional, é um dos três blocos de medicamentos que integram a RENAME. Atualmente, é regulamentado pela Portaria de Consolidação GM/MS no 02 (regras de financiamento e execução) e pela Portaria de Consolidação no 06 (regras de financiamento), ambas de 28 de setembro de 2017 e retificadas no Diário Oficial da União de 13 de abril de 2018.

Este Componente foi aprovado por meio da Portaria GM/MS no 2.981, de 26 de novembro de 2009 e, desde então, tem se consolidado como uma importante estratégia para a garantia do acesso a medicamentos no SUS. Sua principal característica é a garantia da integralidade do tratamento medicamentoso para todas as condições clínicas contempladas no CEAF, por meio das diferentes linhas de cuidado definidas nos PCDT. Em síntese, o CEAF regulamenta estratégias de acesso a medicamentos de alto custo e tratamentos mais elevados e de maior complexidade, sendo que os fármacos do CEAF estão definidos na RENAME (BRASIL, 2020d).

III) Protocolos Clínicos e Diretrizes Terapêuticas (PCDT) e CONITEC. Os PCDT são documentos que estabelecem critérios para o diagnóstico da doença ou do agravo à saúde; o tratamento preconizado, com os medicamentos e demais produtos apropriados, quando couber; as posologias recomendadas; os mecanismos de controle clínico; e o acompanhamento e a verificação dos resultados terapêuticos, a serem seguidos pelos gestores do SUS. Devem ser baseados em evidência científica e considerar critérios de eficácia, segurança, efetividade e custo-efetividade das tecnologias recomendadas. Em termos práticos, os PCDT acabam resultando num documento que descreve quadros e condições verificadas no paciente, com as correspondentes medidas de tratamento.

Lamarão Neto (2019) defende que esse instrumento é um reconhecimento aos profissionais de saúde, na medida em que oferta destaque à necessidade do debate científico como mecanismo apropriado para nortear paradigmas de aceitabilidade no enfrentamento de patologias. Foram incorporados ao ordenamento jurídico através da edição da Lei no ${ }^{\mathrm{o}}$ 12.401/2011, que dispôs sobre a assistência terapêutica e a incorporação de tecnologias em saúde no âmbito do SUS, determinando que cabe ao Estado a incorporação, exclusão ou alteração de 
novos medicamentos, produtos e procedimentos, assim como, a constituição ou alteração dos PCDT.

Deste modo, como cabe ao SUS fornecer as políticas sociais e econômicas por ele formuladas para a promoção, proteção e recuperação da saúde, constata-se que este sistema se filiou à corrente da medicina com base em evidências. Por conta disso, adotaram-se os protocolos clínicos e diretrizes terapêuticas que consolidam um conjunto de critérios que permitem determinar o diagnóstico de doenças e o tratamento correspondente com os medicamentos disponíveis e as respectivas doses. Logo, um fármaco ou tratamento em desconformidade com o protocolo deve ser visto com cautela, pois, tende a contrariar um consenso científico vigente.

A institucionalização dos PCDT advém como meio de formulação de políticas públicas no campo da saúde, no aspecto em que os gestores podem atualizar seus protocolos e, com isso, expandir o sistema de proteção. E mais, é bom dizer, Estados e Municípios possuem legitimidade para criar suas próprias listas de fornecimento de medicamentos. Neste ínterim, a presença de fármacos nos PCDT, cuja dispensação é buscada em juízo, é fator relevante quando o assunto é judicializar sua liberação ao paciente, tanto que nas Jornadas de Direito da Saúde do $\mathrm{CNJ}$ dois enunciados ${ }^{16}$ foram elaborados deixando em perspectiva esta questão.

Dentro deste contexto, em que se busca eficácia, efetividade, segurança e relação custo $x$ benefício, de todos os medicamentos distribuídos pelo SUS, sempre a partir das melhores evidências científicas disponíveis, a CONITEC ganha relevância. A Comissão Nacional de Incorporação de Tecnologias no SUS foi criada em 2011 pela Lei no 12.401, que dispõe sobre a assistência terapêutica e incorporação de tecnologia em saúde no SUS.

É um órgão colegiado de caráter permanente, composto por 13 (treze) membros, incluindo representantes de cada Secretaria do Ministério da Saúde e de diversas instituições, como a ANVISA, o Conselho Nacional de Saúde, o Conselho Nacional de Secretários de Saúde, o Conselho Nacional de Secretarias Municipais de Saúde e o Conselho Federal de Medicina, que tem como objetivo

${ }^{16}$ O Enunciado 11 aduz: "Nos casos em que o pedido em ação judicial seja de medicamento, produto ou procedimento já previsto nas listas oficiais do SUS ou em Protocolos Clínicos e Diretrizes Terapêuticas - (PCDT), o Poder Judiciário determinará a inclusão do demandante em serviço ou programa já existentes no Sistema Único de Saúde - SUS, para o fim de acompanhamento e controle clínico". E, o Enunciado 58 declara: “Quando houver prescrição de medicamento, produto, órteses, próteses ou procedimentos que não constem em lista Relação Nacional de Medicamentos Essenciais - RENAME ou na Relação Nacional de Ações e Serviços de Saúde - RENASES ou nos protocolos do Sistema Único de Saúde - SUS, recomenda-se a notificação judicial do médico prescritor, para que preste esclarecimentos sobre a pertinência e necessidade da prescrição, bem como para firmar declaração de eventual conflito de interesse". 
assessorar o Ministério da Saúde nas atribuições relativas à análise e à elaboração de estudos de avaliação dos pedidos de incorporação, ampliação de uso, exclusão ou alteração de tecnologias em saúde; e na constituição ou na alteração dos PCDT. Por meio de instrumento legal, a Avaliação de Tecnologias em Saúde foi institucionalizada no Brasil como critério indispensável para a tomada de decisão sobre a incorporação tecnológica no SUS (BRASIL, 2020b).

Frise-se, por oportuno, que a incorporação de medicamentos ao SUS se efetua mediante a instauração por qualquer interessado (pessoa física ou jurídica, ou o próprio Ministério da Saúde) de processo administrativo perante a CONITEC. A CONITEC é a responsável por propor a atualização da RENAME, conforme estabelecido no Decreto $\mathrm{n}^{\mathrm{o}}$ 7.646, de 21/12/2011, sendo que a atualização compreende: i) um processo reativo em que os demandantes são órgãos e instituições, públicas ou privadas, ou pessoas físicas; e ii) um processo ativo conduzido por uma subcomissão da CONITEC - a Subcomissão Técnica de Atualização da Rename e do Formulário Terapêutico Nacional. Em ambos os processos, as tecnologias são incorporadas, excluídas ou alteradas no SUS, após avaliação da CONITEC e decisão do secretário da Secretaria de Ciência, Tecnologia, Inovação e Insumos Estratégicos em Saúde do Ministério da Saúde (BRASIL, 2020b).

A Comissão, como dito, tem por objetivo assessorar o Ministério da Saúde nas atribuições relativas à revisão de protocolos clínicos. A legislação estabelece prazo de 180 (cento e oitenta) dias, prorrogável por 90 (noventa) dias, para a tomada de decisão da Comissão nos processos administrativos para incorporação de tecnologias novas. Frisando-se que, é requisito para a análise do CONITEC que o produto esteja registrado na ANVISA. Se ocorrer a recomendação, pela CONITEC, da não incorporação de tecnologia ao SUS, Enunciado ${ }^{17}$ das Jornadas de Direito da Saúde afirma que a determinação judicial de fornecimento deve apontar o fundamento e a evidência científica utilizadas.

Outra questão debatida nas Jornadas de Direito da Saúde, e externalizada via enunciados ${ }^{18}$, diz respeito à necessidade da autoridade judiciária e dos demais atores envolvidos no processo judicial tomarem conhecimento dos pareceres técnicos emitidos pela CONITEC, especialmente em uma conjuntura de

\footnotetext{
${ }_{17}$ O Enunciado 103 explicita: “Havendo recomendação da Comissão Nacional de Incorporação de Tecnologias no SUS - CONITEC pela não incorporação de tecnologia, a determinação judicial de fornecimento deve apontar o fundamento e a evidência científica que afaste a conclusão do órgão técnico, em razão da condição do paciente".

${ }^{18}$ O Enunciado 33 exprime: "Recomenda-se aos magistrados e membros do Ministério Público, da Defensoria Pública e aos Advogados a análise dos pareceres técnicos da Agência Nacional de Saúde Suplementar - ANS e da Comissão Nacional de Incorporação de Tecnologias no SUS Conitec para auxiliar a prolação de decisão ou a propositura da ação". Enquanto o Enunciado 57 assevera: "Em processo judicial no qual se pleiteia o fornecimento de medicamento, produto ou procedimento, é recomendável verificar se a questão foi apreciada pela Comissão Nacional de Incorporação de Tecnologias no SUS - CONITEC".
} 
judicialização, para que suas decisões estejam amparadas por evidência científica ao deferirem fornecimento de fármaco que ainda não consta da lista do SUS.

IV) Medicina Baseada em Evidências (MBE). Para Gebran Neto \& Schulze (2015), a MBE consiste em uma técnica específica para atestar com o maior grau de certeza a eficiência, efetividade e segurança de produtos, tratamentos, medicamentos e exames que foram objeto de diversos estudos científicos, de modo que os verdadeiros progressos das pesquisas médicas sejam transpostos para a prática, revelando-se, desse modo, em uma ferramenta utilizada, em primeiro lugar, no exercício da medicina. É, assim, um poderoso instrumento para a resolução das demandas em que são postulados medicamentos, tratamentos, próteses e/ou outras tecnologias que ainda não foram incorporadas ao SUS.

A Lei $n^{0}$ 12.401/2011 alterou, expressamente, a Lei no 8.080/90 para exigir que na incorporação de novas tecnologias no SUS sejam observadas "as evidências científicas sobre a eficácia, a acurácia, a efetividade e a segurança do medicamento, produto ou procedimento objeto do processo, acatadas pelo órgão competente para o registro ou a autorização de uso", conforme artigo 19-Q, § $2^{\circ}$, I. Em sua obra, Gebran Neto \& Schulze (2015) indicam que existem, pelo menos, sete níveis de estudos da $\mathrm{MBE}$, o que torna a dispensação de fármaco não autorizado pela ANVISA, pela via judicial, uma tarefa complexa, posto que o magistrado precisa estar conectado com conhecimentos e pessoas capacitadas para auxiliá-lo, notadamente quanto a resultados cientificamente comprovados do medicamento pleiteado em juízo.

A tarefa de demonstrar as evidências científicas de medicamentos e produtos distribuídos pelo SUS cabe à CONITEC, nos termos do Decreto n 7.646/2011. E mais, a avaliação dos PCDT que serão manuseados pelo sistema público de saúde brasileiro passa, necessariamente, pela CONITEC, órgão que, como dito linhas pretéritas, tem formação heterogênea, o que atesta que os objetos de estudos passam por rigorosas análises de diversos especialistas que, possuem formação técnica para tal desiderato.

Dentro da judicialização da saúde, em especial quanto ao fornecimento de remédios e substâncias, os magistrados determinam a dispensação de fármacos e outros produtos não incorporados no SUS, por isso é indispensável que a MBE seja invocada por eles na teoria da decisão judicial. A prolação de decisão judicial deferindo pedido de liberação de medicamento não incorporado pelo SUS não pode se basear em um único laudo ou prescrição médica, sem que se apontem evidências científicas confiáveis de que a tecnologia pleiteada é realmente eficaz para o tratamento da doença do paciente em questão.

Ora, se a lei exige que a decisão de incorporação (ou a negativa de incorporação) de medicamento ao Sistema Único de Saúde tenha como fundamentos critérios técnico-científicos, não se deve permitir que esses 
requisitos sejam simplesmente ignorados pelo Poder Judiciário no âmbito de demandas individuais.

Deste modo, quando não houver prova de que o fármaco pleiteado não incorporado pelo SUS não for eficaz à luz da Medicina Baseada em Evidências, não será possível seu deferimento. O sucesso ou não do tratamento postulado na via judicial depende da demonstração da sua eficácia e da sua eficiência e quanto maior for o nível de estudo da MBE, melhor será o resultado pretendido pelo cidadão, autor do processo judicial. A preocupação das autoridades competentes cinge-se em fornecer ao cidadão um produto que será capaz de curar sua patologia sem oferecer riscos demasiados à sua saúde. Efeitos colaterais existem, porém, o limiar do aceitável e tolerável é a questão a nortear a liberação de novos fármacos à população.

A importância das evidências científicas já foi lembrada por alguns enunciados ${ }^{19}$ fixados nas Jornadas de Direito da Saúde, que externalizam sua adoção como procedimento fundamental em busca da segurança aos cidadãos.

\section{SISTEMA INTERPRETATIVO DO STF: RE'S 566.471, 657.718 E 855.178 E SUAS TESES FIXADAS QUANTO AO FORNECIMENTO DE MEDICAMENTOS}

Os Recursos Extraordinários 566.471/RN, 657.718/MG e 855.178/SE foram apreciados pelo STF em sede de Repercussão Geral, com julgamento de mérito, sendo que dois deles fixaram teses vinculantes a partir dos temas tratados, restando à Corte redigir tese para o tema 06 . Respectivamente, o primeiro versa sobre o "Dever do Estado de fornecer medicamento de alto custo a portador de doença grave que não possui condições financeiras para comprá-lo" (tema 06); o segundo, "Dever do Estado de fornecer medicamento não registrado pela ANVISA" (tema 500); e, o terceiro, "Responsabilidade solidária dos entes federados pelo dever de prestar assistência à saúde" (tema 793).

\footnotetext{
${ }^{19}$ O Enunciado 12 expõe: “A inefetividade do tratamento oferecido pelo Sistema Único de Saúde SUS, no caso concreto, deve ser demonstrada por relatório médico que a indique e descreva as normas éticas, sanitárias, farmacológicas (princípio ativo segundo a Denominação Comum Brasileira) e que estabeleça o diagnóstico da doença (Classificação Internacional de Doenças), indicando o tratamento eficaz, periodicidade, medicamentos, doses e fazendo referência ainda sobre a situação do registro ou uso autorizado na Agência Nacional de Vigilância Sanitária Anvisa, fundamentando a necessidade do tratamento com base em medicina de evidências (STJ - Recurso Especial Resp. no 1.657.156, Relatoria do Ministro Benedito Gonçalves - 1a Seção Cível - julgamento repetitivo dia 25.04.2018 - Tema 106)". Por sua vez, o Enunciado 59 informa: "As demandas por procedimentos, medicamentos, próteses, órteses e materiais especiais, fora das listas oficiais, devem estar fundadas na Medicina Baseada em Evidências - MBE". Por fim, o Enunciado 97 salienta que: "As solicitações de terapias alternativas não previstas no rol de procedimentos da ANS, tais como equoterapia, hidroterapia e métodos de tratamento, não são de cobertura e/ou custeio obrigatório às operadoras de saúde se não estiverem respaldadas em Medicina Baseada em Evidência e Plano Terapêutico com Prognóstico de Evolução".
} 
Iniciaremos com o RE 855.178 RG/SE, cuja tese de Repercussão Geral sobre o tema 793 foi fixada em 23 de maio de 2019, e possui o seguinte teor:

Os entes da federação, em decorrência da competência comum, são solidariamente responsáveis nas demandas prestacionais na área da saúde, e diante dos critérios constitucionais de descentralização e hierarquização, compete à autoridade judicial direcionar o cumprimento conforme as regras de repartição de competências e determinar o ressarcimento a quem suportou o ônus financeiro.

A tese, elaborada a partir do julgamento de Embargos de Declaração opostos no RE 855.178, basicamente, reafirmou a jurisprudência do STF, assentando que as prestações de saúde pleiteadas em sede de judicialização se inserem no rol dos deveres do Estado, sendo que existe uma responsabilidade solidária dos entes da Federação, podendo, por isso, qualquer um deles, em conjunto ou isoladamente, figurar no polo passivo da demanda. A Corte ratificou a regra de solidariedade, deixando ao magistrado a tarefa de direcionar o cumprimento das determinações conforme as regras de repartição de competências administrativas e financeiras fixadas dentro do SUS.

Aqui, convém mencionar, a dispensação da tecnologia requerida faz parte da política pública do SUS, o que levou à fixação do entendimento de que todos os entes são responsáveis pelo atendimento da demanda, e isso precisa ficar claro. Entretanto, a Corte não demarcou a atribuição de cada ente federativo, ou seja, não disse a quem caberia a responsabilidade administrativa, reservando ao julgador essa incumbência, bem como, deixando a seu critério a indicação dos meios de ressarcimento ao ente que fora condenado e que, após, terá que demandar o verdadeiro responsável pela efetivação da prestação de saúde requerida.

A oportunidade de fixar as atribuições de cada ente federativo no tocante à assistência farmacêutica era no RE 855.178, exatamente por se tratar de precedente vinculante. Ademais, caminhos podem auxiliar o julgador. A RENAME comporta 3 (três) blocos de fármacos (componentes básicos, estratégicos e especializados), cada um deles observando um padrão de aquisição e distribuição, tanto que o Enunciado 8 das Jornadas de Direito da Saúde firmou: “Nas apreciações judiciais sobre ações e serviços de saúde devem ser observadas as regras administrativas de repartição de competência entre os entes federados" (BRASIL, 2020g).

Assim, cabe ao julgador, dentro de litígio em que se peça dispensação de tecnologia ofertada em política pública do SUS, averiguar, dentro do âmbito de aquisição e distribuição, qual é o ente responsável por aquele fármaco, insumo ou procedimento, ou seja, deve o juiz conhecer as normas do SUS, em especial, a 
normativa referente ao financiamento da assistência farmacêutica. Por isso, deverá a autoridade judicial modular os efeitos de sua decisão. Outrossim, caso o medicamento não tenha sido incorporado pelo SUS, isto é, não faz parte da RENAME, nem dos PCDT, não foi registrado na ANVISA, nem autorizado pela CONITEC, então, a competência para processamento e julgamento recai, necessariamente, sobre a Justiça Federal.

O artigo 19-Q da Lei no 8.080/90 assevera que a incorporação, a exclusão ou a alteração pelo SUS de novas tecnologias, assim como, a constituição ou a alteração de protocolo clínico ou de diretriz terapêutica, são atribuições do Ministério da Saúde, assessorado pela CONITEC, portanto, a União tem a legitimidade passiva para figurar na lide, nos termos do artigo 109, inciso I, da Constituição. Nesse sentido, foi editado o Enunciado 78 das Jornadas de Direito da Saúde: “Compete à Justiça Federal julgar as demandas em que são postuladas novas tecnologias ainda não incorporadas ao Sistema Único de Saúde - SUS" (ENUNCIADOS, on line).

Caso o magistrado da Justiça Estadual receba o petitório, deverá indeferir a petição inicial e extingui-lo sem resolução de mérito, viabilizando que o cidadão ajuíze a demanda perante o Juízo competente. Não poderá o juiz estadual obrigar a União a ser incorporada na lide conquanto sua inclusão no polo passivo do litígio atrai a competência da Justiça Federal.

Por derradeiro, quando o pleito versar sobre fármacos de elevado valor e haja complexidade do diagnóstico e tratamento, acompanhado no âmbito do SUS em serviços de referência em doenças raras, deve-se ter em perspectiva que, por conta da possibilidade de modulação dos efeitos da decisão pelo magistrado, e levandose em conta a necessária sustentabilidade do sistema de saúde, quanto mais complexo o atendimento, mais a manifestação judicial deve se afastar do ente local. Os municípios devem ser afastados de demandas caras e complexas, e a responsabilidade deve recair sobre a União e, em menor grau, sobre o Estado. Essa diretiva, que pode ser materializada pela modulação, racionaliza a prestação jurisdicional. A impossibilidade orçamentária da maioria dos munícipios brasileiros inviabiliza a aquisição de medicamentos de alto valor.

Em sequência, passemos a abordar o RE 657.718 RG/MG, cuja tese de Repercussão Geral sobre o tema 500 foi firmada em 22 de maio de 2019, e possui o seguinte teor:

1. O Estado não pode ser obrigado a fornecer medicamentos experimentais. 2. A ausência de registro na ANVISA impede, como regra geral, o fornecimento de medicamento por decisão judicial. 3. É possível, excepcionalmente, a concessão judicial de medicamento sem registro sanitário, em caso de mora irrazoável da ANVISA em apreciar o pedido (prazo superior ao previsto na Lei $\mathrm{n}^{\mathrm{o}}$ 13.411/2016), quando preenchidos três requisitos: (i) a 
existência de pedido de registro do medicamento no Brasil (salvo no caso de medicamentos órfãos para doenças raras $\mathrm{e}$ ultrarraras);(ii) a existência de registro do medicamento em renomadas agências de regulação no exterior; e (iii) a inexistência de substituto terapêutico com registro no Brasil. 4. As ações que demandem fornecimento de medicamentos sem registro na ANVISA deverão necessariamente ser propostas em face da União.

O tema 500 discutia, em síntese, se existia obrigatoriedade de o Poder Público fornecer medicamentos que ainda não foram autorizados pelas autoridades sanitárias competentes, e, por consequência, ainda não foram incorporados pelo SUS. Em outros termos, o cerne da discussão residia na necessidade de registro prévio perante a ANVISA, assim como, ressaltava a singular importância dos PCDT, enquanto instrumentos de consenso resultantes da atividade científica.

A questão é, mesmo que uma tecnologia não tenha recebido registro no Brasil, isso não significa que ela não tenha eficácia para o paciente. Dentro da demanda, pode o autor demonstrar que o fármaco será eficaz para o combate à sua patologia, ajudando-o na recuperação de sua saúde. Para tanto, irá demonstrar a existência de resultado científico comprovando suas alegações, inclusive, trazer ao conhecimento do Juízo a aprovação de determinado medicamento pela FDA (Agência Federal Norte-Americana que regula os medicamentos), ou pela EMA (Agência Europeia do Medicamento) ou até pela PMDA (Agência de Produtos Farmacêuticos e Dispositivos Médicos do Japão). E mais, deve demonstrar que o produto dispensado pela rede pública é insatisfatório para seu tratamento ou, simplesmente, que inexiste. Outras condições foram fixadas, porém, a instrução processual esclarecerá a questão particular do demandante.

Merece atenção, outrossim, que nos casos em que se pleiteia medicamento e/ou tratamento não existente no SUS, a atribuição para a incorporação passa pela CONITEC, órgão vinculado e de consulta do Ministério da Saúde, logo, a União terá interesse na causa, o que faz com que a competente para analisar e julgar o feito seja a Justiça Federal. $\mathrm{O}$ item 4 da tese fixada deixa essa condição muito nítida. Além dela, o Enunciado 78 das Jornadas de Direito da Saúde já tinha definido esta interpretação acerca da competência da Justiça Federal e não da Justiça Estadual.

E mais, outros dois Enunciados das Jornadas de Direito da Saúde ${ }^{20}$, auxiliares na tomada de decisão pelo juiz em questões de judicialização, corroboram com o

\footnotetext{
${ }^{20} \mathrm{O}$ Enunciado 06 diz: "A determinação judicial de fornecimento de fármacos deve evitar os medicamentos ainda não registrados na Anvisa ou em fase experimental, ressalvadas as exceções expressamente previstas em lei (STJ - Recurso Especial Resp. no 1.657.156, Relatoria do Ministro
} 
entendimento fixado na tese aqui analisada, de que o registro na ANVISA é condição essencial para o deferimento do pleito, e funciona como regra geral. Um dos mais importantes desígnios do SUS é a vigilância sanitária, enquanto responsável por promover ações que visem salvaguardar a saúde dos cidadãos; se um determinado fármaco pode recuperar e promover a saúde humana, é preciso ter a consciência de que ele também pode gerar danos. Por isso a necessidade de se ter uma autoridade sanitária apta a conceder um registro sanitário, atestando qualidade, segurança e eficácia do medicamento.

A regra, portanto, é que não existe obrigação do Estado dispensar fármaco não registrado na ANVISA via judicialização. Mas, o STF elencou requisitos e critérios que autorizam, excepcionalmente, a dispensação, e devem ser observados cumulativamente pela parte.

Uma delas é a mora irrazoável da ANVISA em apreciar o pedido formal de registro do medicamento no Brasil. Aqui, deve-se levar em consideração a inteligência da Lei no 13.411/2016, que acresceu o artigo 17-A à Lei no 6.360/1976, para dizer que, os prazos estabelecidos para a decisão final nos processos de registro e de alteração pós-registro de fármaco levarão em conta alguns critérios, um deles é que os prazos máximos para a decisão final nos processos de registro e de alteração pós-registro de medicamento serão: I - para a categoria prioritária, de cento e vinte dias e de sessenta dias, contados a partir da data do respectivo protocolo de priorização; e, II - para a categoria ordinária, de trezentos e sessenta e cinco dias e de cento e oitenta dias, contados a partir da data do respectivo protocolo de registro ou de alteração pós-registro.

Considerando o exposto acima, constata-se que, se o prazo máximo de 01 (um) ano após o protocolo do pedido de registro da medicação junto à ANVISA expirar, e, somando-se a isso, existir o registro do fármaco em agências de regulação no exterior, a exemplo da FDA e EMA, e ausente alternativa terapêtica satisfatória no Brasil, nasce para o cidadão a possibilidade de pleitear o medicamento perante o Poder Judiciário, especificamente na Justiça Federal. A tese acabou por romper com a solidariedade entre os entes federados, definindo que, preenchidos os requisitos para determinação judicial de fornecimento do medicamento, o ente público que deverá suportar o custeio da tecnologia sem registro na ANVISA é a União.

Benedito Gonçalves - 1aㅗ Seção Cível - julgamento repetitivo dia 25.04.2018 - Tema 106)". Por sua vez, o Enunciado 50 exprime que: "Não devem ser deferidas medidas judiciais de acesso a medicamentos e materiais não registrados na Agência Nacional de Vigilância Sanitária ANVISA ou deferidas medidas judiciais que assegurem acessos a produtos ou procedimentos experimentais (Tema 106 STJ - STJ - Recurso Especial Resp. nº 1.657.156, Relatoria do Ministro Benedito Gonçalves - 1ª Seção Cível - julgamento repetitivo dia 25.04.2018 e RE 566471/RN, RE 657718/MG do STF)". 
Outra exceção diz respeito a pedido judicial de medicamentos órfãos para doenças raras ${ }^{21}$ e ultrarraras. O STF entendeu que o cidadão pode requerer judicialmente a dispensação de fármaco para tratamento de doenças raras e ultrarraras, sendo que, neste caso, é dispensável pedido prévio de registro junto à ANVISA. Para os chamados medicamentos órfãos, mostra-se forçoso ao autor da demanda comprovar que a tecnologia foi registrada em alguma agência de regulação como a FDA, EMA, PMDA por exemplo, bem como, que não há alternativa terapêutica registrada e satisfatória no país. Em complemento, segundo Silva (2000), medicamentos órfãos são fármacos potencialmente úteis, que não estão disponíveis no mercado, cuja exploração não é considerada lucrativa pela indústria farmacêutica por motivos como a dificuldade de produção ou, ainda, por serem destinados ao tratamento de doenças raras, que atingem um reduzido número de pessoas; por conta disso, seus custos são elevadíssimos.

Entrementes, considerando a situação emergencial ocasionada pela disseminação do SARS-CoV-2, que teve início no mês de dezembro de 2019 na cidade Wuhan (China) (OPAS, on line), o Brasil decretou no dia 20 de março de 2020, por meio do Decreto Legislativo no 6, o reconhecimento do Estado de Calamidade Pública, em virtude da Pandemia ocasionada pelo Coronavírus (COVID-19) e, desde então, dois medicamentos (Cloroquina ou Hidroxicloroquina e Azitromicina) passaram a fazer parte do rol de fármacos que, apesar da inexistência de protocolo clínico, ou seja, porque não possuem evidências científicas, são utilizados para combater os efeitos do COVID-19.

O Ministério da Saúde (BRASIL, 2020c) reconhece que não há evidências científicas suficientes que comprovem a eficácia desses medicamentos para casos de coronavírus, contudo, editou a Nota Informativa no 6/2020DAF/SCTIE/MS, em $1^{0}$ de abril de 2020, indicando a cloroquina como terapia adjuvante no tratamento de formas graves do COVID-19. Essa liberação de uso prevê cinco dias de tratamento e é indicado apenas para pacientes hospitalizados. A Cloroquina ou Hidroxicloroquina (análogo) é um medicamento cuja segurança e eficácia está bem definida para indicações clínicas de lúpus, malária e artrite reumatoide, havendo protocolos perante o SUS, inclusive, fazendo parte da RENAME.

Em 20 de maio de 2020, através de uma Orientação, o Ministério da Saúde (BRASIL, 2020e) ampliou o uso da cloroquina, indicando-a para o tratamento precoce da COVID-19 no âmbito do SUS. Deste modo, se o paciente manifestar sinais e sintomas leves, sinais e sintomas moderados ou sinais e sintomas graves, os médicos poderão receitá-la, em conjunto com a azitromicina, desde que

\footnotetext{
${ }^{21}$ Sugere-se a leitura, para aprofundamento, da obra: MORO, Rosangela Wolff. Doenças raras $e$ políticas públicas: entender, acolher e atender. São Paulo, SP: Matrix Editora, 2020.
} 
aquele assine, por livre iniciativa, Termo de Ciência e Consentimento, deixando claro sua total ciência quanto à inexistência de garantia de resultados positivos para a COVID-19 e que o fármaco proposto pode apresentar diversos efeitos colaterais, podendo evoluir até ao óbito. A Orientação do Ministério da Saúde, que não veio acompanhada de assinatura de médico(a), deixa claro, uma vez mais, que "até o momento não existem evidências científicas robustas que possibilitem a indicação de terapia farmacológica específica para a COVID-19" (BRASIL, 2020e, p. 1).

Face a isso, e levando em conta a tese fixada no tema 500 da Repercussão Geral do STF, se o cidadão pleitear judicialmente esse fármaco, deverá fazê-lo perante qual Justiça? Tanto a Cloroquina ou Hidroxicloroquina (análogo), e a própria Azitromicina, não estão registrados na ANVISA para a finalidade de combater os efeitos do COVID 19. Deste modo, como não há protocolo oficial para seu uso contra o novo coronavírus, justamente por inexistirem evidências científicas, mas, apenas uma nota técnica sucedida por uma orientação, seu uso será experimental, logo, como a inserção passa pela CONITEC, vinculada ao Ministério da Saúde, então, as demandas devem ser direcionadas para a Justiça Federal. E mais, eventual ajuizamento na Justiça Estadual com deferimento do pleito, ou seja, com prolação de julgamento meritório, cabe Reclamação Constitucional para o STF, na medida em que a autoridade estadual desafiou decisão vinculante, eis que a tese deve ser observada por todo o Poder Judiciário.

Pois bem, considerando que a tese firmada no tema 500 definiu a questão dos medicamentos não registrados na ANVISA, o próximo tema tratado visa fixar entendimento quanto à obrigação do Estado fornecer fármaco registrado, disponível no mercado, mas de alto custo e não incorporado à política pública de dispensação gratuita de medicamentos do SUS.

Chega-se, assim, ao RE 566.471 RG/RN, cujo tema 06 versa sobre o "Dever do Estado de fornecer medicamento de alto custo a portador de doença grave que não possui condições financeiras para comprá-lo", tendo sido julgado, seu mérito, em 11 de março de 2020, contudo, sem ainda ter sido fixada uma tese. Ademais, a Suprema Corte decidiu a questão, vamos a ela.

O Plenário do STF, por maioria (8x1), decidiu que o Estado não é obrigado, como regra, a fornecer medicamentos de alto custo solicitados judicialmente, quando não estiverem previstos no Componente Especializado da Assistência Farmacêutica do SUS. A maioria dos Ministros desproveu o recurso, tendo como condutor o voto do relator, ministro Marco Aurélio, entendendo que, nos casos de remédios de alto custo não disponíveis no sistema, o Estado até pode ser obrigado a fornecê-los, desde que comprovadas a extrema necessidade do medicamento e a incapacidade financeira do paciente e de sua família para sua aquisição.

$\mathrm{O}$ entendimento reafirma que o Estado não pode ser obrigado a fornecer fármacos não registrados na agência reguladora, no entanto, situações excepcionais poderão levar o Judiciário a determinar a dispensação, e serão 
indicadas por ocasião da tese a ser debatida em Plenário em sessão futura. Por enquanto, a posição assentada por alguns ministros em seus votos poderá lançar luzes sobre o delineamento da tese que ainda será firmada pelo STF.

Para o ministro Alexandre de Moraes, o excesso de judicialização da saúde tem prejudicado políticas públicas, pois, decisões judiciais favoráveis a poucas pessoas, por mais importantes que sejam seus problemas, comprometem o orçamento total destinado a milhões de pessoas que dependem do SUS, colocando em risco o equilíbrio da própria política de saúde, em especial porque inexiste mágica orçamentária e não há nenhum país do mundo que garanta acesso a todos os medicamentos e tratamentos de forma generalizada para todos, existem limitações de recursos, e isso é uma realidade.

Continuando, declarou que a regra é que o Estado só forneça o medicamento em casos excepcionais, como: comprovação de hipossuficiência do paciente; existência de laudo médico comprovando a necessidade do medicamento e elaborado pelo perito de confiança do magistrado; certificação pela CONITEC de que o medicamento pleiteado não foi indeferido e a inexistência de fármaco substituto nas listas oficiais de dispensação.

O ministro Luís Roberto Barroso, acompanhando a maioria, também negou provimento ao recurso e disse que o Estado não pode ser obrigado por decisão judicial a fornecer medicamento não incorporado pelo SUS, independentemente de custo, salvo hipóteses excepcionais, em que preenchidos 05 (cinco) requisitos, são eles: incapacidade financeira de arcar com o custo correspondente; demonstração de que a não incorporação do medicamento não resultou de decisão expressa dos órgãos competentes; inexistência de substituto terapêutico incorporado pelo SUS; comprovação de eficácia do medicamento pleiteado à luz da medicina baseada em evidências; propositura da demanda necessária em face da União, já que a responsabilidade pela decisão final sobre a incorporação ou não de medicamentos é exclusiva desse ente federativo.

O relator do caso, Ministro Marco Aurélio, defendeu a tese de que o reconhecimento do direito individual ao fornecimento, pelo Estado, de medicamento de alto custo, não incluído em Política Nacional de Medicamentos ou em Programa de Medicamentos de Dispensação em Caráter Excepcional (atual CEAF), constante de rol dos aprovados, depende da demonstração da imprescindibilidade - adequação e necessidade -, da impossibilidade de substituição do fármaco e da incapacidade financeira do enfermo e da falta de espontaneidade dos membros da família solidária em custeá-lo, respeitadas as disposições sobre alimentos dos artigos 1.694 a 1.710 do Código Civil, e assegurado o direito de regresso. Basicamente, o ministro elencou três condições para o reconhecimento do direito individual ao fornecimento de medicamento de alto custo. 
Dentre os inúmeros argumentos levantados e indicados em algumas das manifestações acima mencionadas, e das outras que aqui não se colacionou, constata-se que existe uma tendência a reconhecer que não existe obrigação do Poder Público em fornecer medicamentos não constantes das listas de dispensação do SUS, abrindo exceção à essa regra por conta dos cidadãos vulneráveis. Ficou claro, dentre as condicionantes assinaladas pela maioria, que só poderão pleitear o fármaco de alto custo em juízo quem comprovar a incapacidade financeira do paciente e de sua família solidária e a extrema necessidade do medicamento.

Inúmeros outros requisitos foram suscitados, como a juntada de: laudos elaborados por perito de confiança do magistrado; laudos deverão estar fundamentados na medicina baseada em evidências; comprovação de que não há substituto terapêutico eficaz ou medicamento similar já disponibilizado pelo SUS; fármaco esteja em análise para incorporação ao SUS e o prazo para análise tenha extrapolado o lapso legal estabelecido. Enfim, uma série de condicionantes que precisarão ser discutidas e escolhidas visando à fixação da tese.

Deste modo, a decisão do STF no tema 06 é no sentido de que, em caráter excepcional, é possível a concessão de fármacos não registrados na lista da Anvisa. Todavia, as situações excepcionais ainda serão definidas na formulação da tese, o que ocorrerá em vindoura sessão. Frisando-se que, como estamos lidando com fármacos não registrados, a competência para julgamento de eventuais demandas judiciais recai sobre a Justiça Federal, considerando que é o Ministério da Saúde, por meio da CONITEC, quem elabora os estudos técnicos para incorporação ou não, de determinado medicamento nas listas do SUS. Tratase, portanto, de avaliação técnica e juízo de conveniência e oportunidade exercido única e exclusivamente pela União, ou seja, uma discricionariedade vinculada à norma, logo, acredita-se que aquela será a demandada na lide, até porque, pensar em um município como polo passivo em demanda com fármacos de elevado valor, como os medicamentos órfãos, poderia levar a economia do ente municipal ao colapso.

Cabe aguardar o plenário da Corte, que fixará a tese e terá, assim, todo um sistema ou microssistema interpretativo a delinear as decisões judiciais em sede de judicialização, em especial, no tocante ao fornecimento de medicamentos. A tríade vinculante do STF converte-se em diretivas que emprestam racionalidade nos julgamentos vindouras, repercutindo no uso otimizado dos recursos públicos. A interpretação delineada pelas teses inaugura um novo momento na judicialização para fornecimento de medicamentos, pautada em critérios delimitados que, ao fim, asseguram a imprescindível e salutar segurança jurídica nas manifestações judiciais envolvendo prestações de saúde.

\section{CONCLUSÃO}


Visando firmar parâmetros e limites claros à judicialização, em especial, no tocante à dispensação de medicamentos, o STF escolheu três Recursos Extraordinários paradigmáticos, fixando temas cujo julgamento de mérito resultaria em teses a serem utilizadas em todas as demandas de saúde pelo país, considerando seu efeito vinculante. Basicamente, o tema 06 (RE 566.471) trata de medicamentos de alto custo, registrados na ANVISA, disponíveis no mercado brasileiro, mas não incorporados à política pública de dispensação gratuita do SUS. O tema 500 (RE 657.718) trata de medicamentos não registrados na ANVISA. Por sua vez, o tema 793 (RE 855.178) versa sobre a responsabilidade solidária dos entes federados quanto ao dever de prestar assistência à saúde, notadamente para medicamento ou tratamento já incorporado ao SUS.

A afirmação da solidariedade entre União, Estados e Municípios, para tecnologias dispensadas pelo SUS, conforme tese para o tema 793, confere maior proteção ao cidadão e reafirmação da inteligência da CRFB/88 que já previa tal situação. Deste modo, o indivíduo aciona o Judiciário e, com a prolação de sentença condenatória, caberá ao juiz da causa direcionar o cumprimento da obrigação ao ente federativo competente administrativamente, ou seja, irá modular os efeitos de sua decisão, bem como, determinará o ressarcimento a quem suportou o ônus financeiro indevidamente. Neste contexto, acredita-se que o magistrado deve ser contundente em sua manifestação, basicamente porque ocorreu um problema de gestão, seja no planejamento, na licitação, enfim, complicação que poderia ser evitada pelo gestor.

Quanto ao tema 500, sua tese fixou o entendimento de que não existe obrigação do Poder Público dispensar medicamento não registrado na ANVISA. Porém, a Corte elencou requisitos e critérios que autorizam, excepcionalmente, o fornecimento, contudo, devem ser observados de maneira cumulativa. Assim, ocorrerá concessão judicial de medicamento sem registro sanitário, desde que, seja demonstrada a mora irrazoável da ANVISA em apreciar o pedido, cumulado com: I) a existência de pedido de registro do medicamento no Brasil (salvo no caso de medicamentos órfãos para doenças raras e ultrarraras); II) a existência de registro do medicamento em renomadas agências de regulação no exterior; e, III) a inexistência de substituto terapêutico com registro no Brasil. Além disso, a competência para processamento e julgamento desses feitos será da Justiça Federal, considerando que a ausência de registro perante a autoridade sanitária competente atrai a necessária participação da União na lide.

O STF ainda não fixou tese para o tema 6, porém, o mérito da causa foi resolvido, onde se concluiu não existir obrigação do Poder Público em fornecer medicamentos de elevado valor não constantes das listas de dispensação do SUS. Todavia, poderá ser obrigado, excepcionalmente, desde que preenchidos determinados requisitos que, os próprios Ministros suscitaram em seus votos, como: demonstração de hipossuficiência financeira; laudo médico comprovando a 
necessidade do fármaco; laudos serem elaborados por perito de confiança do magistrado; laudos estiverem fundamentados na medicina baseada em evidências; comprovação de que não há substituto terapêutico ou medicamento similar já dispensado pelo SUS; e, o fármaco esteja em análise para incorporação ao SUS e o prazo para análise tenha extrapolado. É necessário aguardar a fixação da tese para se ter os critérios efetivamente escolhidos.

De uma maneira geral, o que se extrai das teses e do mérito do RE 566.471, é que o STF orientou seu sistema interpretativo concernente à judicialização pela dispensação de medicamento na utilização da Medicina Baseada em Evidências, técnica apta a certificar a eficácia, a acurácia, a efetividade e a segurança do medicamento, produto ou procedimento pleiteado, privilegiando as tecnologias já registradas no país e pertencentes à lista de dispensação do SUS, na medida em que observaram todo o procedimental de certeza científica.

O ensaio buscou colocar em discussão, justamente, os parâmetros interpretativos vinculantes determinados pelo STF, o que repercutirá, em nossa leitura, na resposta à judicialização, que alcançará maior racionalização, na medida em que orientada por critérios e limites específicos, bem delimitados, capazes de deixar em perspectiva a necessária utilização das evidências científicas comprovadas como critério essencial, assim como, o salutar controle sanitário quanto à eficácia e segurança do fármaco, o que se materializa com o registro na ANVISA.

Essas são, agora, as principais orientações vinculantes a todos os magistrados do país, levando à resposta ao problema de pesquisa proposto no sentido de que o sistema interpretativo adotado pelo STF ofertou maior racionalização às soluções judiciais conferidas a essas contendas, assegurando a integridade do direito à saúde. Exceções existem, e foram explicitadas pela Corte, devendo ser manejadas em estrita conformação ao preceituado na tese, que, repita-se, tem efeito vinculante.

A resolução dos casos levados ao conhecimento do Judiciário, em especial quando pleiteiam a dispensação de fármacos, devem estar balizados por premissas técnicas que consigam, a um só tempo, reverenciar o direito fundamental do cidadão à saúde, como também, contemplar as normas de controle sanitário seguidas pela autoridade sanitária brasileira, ANIVISA, cuja atuação se volta para a eliminação, diminuição e prevenção de riscos à saúde humana. A judicialização pelo fornecimento de medicamentos deve caminhar em sintonia com os métodos científicos que atestam a eficácia do que se busca em juízo.

Evidentemente, isso não afasta o dever primacial do Executivo em expandir, cada vez mais, a lista de medicamentos de dispensação gratuita à população, inclusive os de elevado valor, obviamente, observando critérios científicos para tal, bem como, aprimorar sua gestão no aspecto em que as tecnologias que já fazem parte das políticas públicas do SUS não podem deixar de serem 
distribuídas à população. A gestão eficiente, quanto ao que já é fornecido, como a inclusão de novos fármacos, são medidas que diminuirão a incidência da judicialização.

Um outro caminho desponta, em nosso sentir, como imperativo para diminuir a judicialização da saúde, qual seja, um orçamento público capaz de, efetivamente, concretizar o conteúdo do direito à saúde na perspectiva das necessidades das pessoas, para que elas possam ficar em condições de realizar seus projetos de vida. Apenas com a disponibilização dos recursos públicos necessários, será possível ofertar ações e serviços adequados à população, seja na atenção básica, na média ou alta complexidade. A saúde deve ser prioridade, na medida que a elevação do seu status à categoria de direito fundamental, a torna bem jurídico indispensável.

Nada obstante, se ainda assim o cidadão judicializar alguma questão, haverá à disposição do julgador parâmetros seguros, capazes de auxiliá-lo na tarefa de bem decidir a demanda, colaborando para que a resposta do Poder Judiciário esteja imbuída de racionalidade e reflita a imprescindível segurança jurídica, sempre com base nas evidências científicas.

\section{REFERÊNCIAS}

ARAUJO, Luiz Alberto David \& NUNES JÚNIOR, Vidal Serrano. Curso de direito constitucional. 22. ed. rev. e atual. até a EC 99 de 14 de dezembro de 2017. São Paulo: Editora Verbatim, 2018.

BRAGA, Paulo Vitor Bergamo. Judicialização, assistência farmacêutica e argumentação. Análise da jurisprudência do TRF da $3^{\underline{a}}$ Região. In: BUCCI, Maria Paula Dallari; DUARTE, Clarice Seixas (Coords.). Judicialização da saúde: a visão do poder executivo. São Paulo: Saraiva, 2017, p. 368 - 394.

BRASIL. Constituição da República Federativa do Brasil de 1988. Vade Mecum Saraiva. 25. ed. atual. e ampl. - São Paulo: Saraiva Educação, 2018.

BRASIL. Decreto nº 7.508, de 28 de junho de 2011. Vade Mecum Saraiva. 25. ed. atual. e ampl. - São Paulo: Saraiva Educação, 2018.

BRASIL. Decreto no 7.646, de 21 de dezembro de 2011. Vade Mecum Saraiva. 25. ed. atual. e ampl. - São Paulo: Saraiva Educação, 2018.

BRASIL. Lei federal 6.360, de 23 de setembro de 1976. Vade Mecum Saraiva. 25. ed. atual. e ampl. - São Paulo: Saraiva Educação, 2018. 
BRASIL. Lei federal 8.080, de 19 de setembro de 1990. Vade Mecum Saraiva. 25. ed. atual. e ampl. - São Paulo: Saraiva Educação, 2018.

BRASIL. Lei federal 12.401, de 28 de abril de 2011. Vade Mecum Saraiva. 25. ed. atual. e ampl. - São Paulo: Saraiva Educação, 2018.

BRASIL. Agência Nacional de Vigilância Sanitária. Institucional. Disponível em: http://portal.anvisa.gov.br/institucional. Acesso em: 02 maio 2020.

BRASIL. Conselho Nacional de Justiça. Atos Normativos. 2020f. Disponível em: https://www.cnj.jus.br/atos_normativos/. Acesso em: 02 abr. 2020.

BRASIL. Conselho Nacional de Justiça. Relatório Justiça em Números 2019. Anobase 2018. 2019. Disponível em: https://www.cnj.jus.br/wpcontent/uploads/conteudo/arquivo/2019/08/justica_em_numeros20190919.pdf. Acesso em 03 abr. 2020.

BRASIL. Conselho Nacional de Justiça. Enunciados das Jornadas de Direito da Saúde. 2020g. Disponível em: https://www.cnj.jus.br/wpcontent/uploads/2019/03/e8661c101b2d80ec95593d03dc1f1d3e.pdf. Acesso em: 09 mar. 2020.

BRASIL. Decreto Legislativo 06, de 20 de março de 2020. Disponível em: http://www.planalto.gov.br/CCIVIL_03/Portaria/DLG6-2020.htm. Acesso em: 03 maio 2020.

BRASIL. Ministério da Saúde. Resolução nº 338, de 06 de maio de 2004. Disponível em: https://bvsms.saude.gov.br/bvs/saudelegis/cns/2004/res0338_06_05_2004.html. Acesso em: 18 maio 2020.

BRASIL. Ministério da Saúde. Entendendo a Incorporação de Tecnologias em Saúde no SUS: como se envolver. Brasília: Ministério da Saúde, 2016. Disponível em:

http://bvsms.saude.gov.br/bvs/publicacoes/entendendo_incorporacao_tecnologias _sus_envolver.pdf. Acesso em: 02 maio 2020.

BRASIL. Ministério da Saúde Relação Nacional de Medicamentos Essenciais Rename. Brasília: Ministério da Saúde, 2020a. Disponível em: https://saude.gov.br/saude-de-a-z/rename. Acesso em: 30 abr. 2020. 
BRASIL. Ministério da Saúde. Relação Nacional de Medicamentos Essenciais: Rename 2020. Brasília: Ministério da Saúde, 2020b. Disponível em: https://bvsms.saude.gov.br/bvs/publicacoes/relacao_medicamentos_rename_2020. pdf. Acesso em: 30 abr. 2020.

BRASIL. Ministério da Saúde. Uso da Cloroquina como terapia adjuvante no tratamento de formas graves do COVID-19. 2020c. Disponível em:

https://portalarquivos.saude.gov.br/images/pdf/2020/April/14/Nota-Informativa06-Cloroquina-DAF-SCTIE.pdf. Acesso em: 13 maio 2020.

BRASIL. Ministério da Saúde. Componente Especializado da Assistência Farmacêutica (CEAF). Brasília: Ministério da Saúde, 2020d. Disponível em: https://www.saude.gov.br/assistencia-farmaceutica/medicamentosrename/componente-especializado-da-assistencia-farmaceutica-ceaf. Acesso em: 13 maio 2020.

BRASIL. Ministério da Saúde. Orientações do Ministério da Saúde para manuseio medicamentoso precoce de pacientes com diagnóstico da COVID-19. Publicada em 20 de maio de 2020. Disponível em: https://saude.gov.br/images/pdf/2020/May/20/ORIENTA----ES-D-PARAMANUSEIO-MEDICAMENTOSO-PRECOCE-DE-PACIENTES-COM-DIAGN-STICO-DA-COVID-19.pdf. Acesso em: 20 maio 2020.

BRASIL. Supremo Tribunal Federal. RE 566.471-RN. Tema 06 da Sistemática de Repercussão Geral. Relator: MIN. MARCO AURÉLIO. Brasília, 11.03.2020. Disponível em: http://www.stf.jus.br/portal/processo/verProcessoDetalhe.asp?incidente=2565078. Acesso em: 28 abr. 2020.

BRASIL. Supremo Tribunal Federal. RE 657.718-MG. Tema 500 da Sistemática de Repercussão Geral. Relator: MIN. MARCO AURÉLIO. Brasília, 22.05.2020.

Disponível em:

http://www.stf.jus.br/portal/jurisprudenciaRepercussao/verProcessoDetalhe.asp?i ncidente $=4143144$. Acesso em: 28 abr. 2020.

BRASIL. Supremo Tribunal Federal. RE 855.178-SE. Tema 793 da Sistemática de Repercussão Geral. Relator: MIN. MIN. LUIZ FUX. Brasília, 23.05.2020.

Disponível em:

http://www.stf.jus.br/portal/jurisprudenciaRepercussao/verProcessoDetalhe.asp?i ncidente $=4678356$. Acesso em: 28 abr. 2020. 
BRITO FILHO, José Claudio Monteiro de. Direito fundamental à saúde: propondo uma concepção que reconheça o indivíduo como seu destinatário. Caderno da Escola Superior da Magistratura do Estado do Pará, v. 1, no 1, 2008, p. 136-145.

FERREIRA, Vanessa Rocha. Direito fundamental à saúde: uma análise do posicionamento do STF à luz do liberalismo de princípios. Rio de Janeiro: Lumen Juris, 2019.

GEBRAN NETO, João Pedro; SCHULZE, Clenio Jair. Direito à Saúde: Análise à luz da judicialização. Porto Alegre: Verbo Jurídico, 2015.

INSTITUTO DE ENSINO E PESQUISA (INSPER). Judicialização da Saúde no Brasil: Perfil das demandas, causas e propostas de solução. Mar. 2019. Relatório Analítico Propositivo - Justiça Pesquisa (CNJ). Disponível em:

https://www.cnj.jus.br/agendas/iii-jornada-da-saude/. Acesso em: 02 abr. 2020.

JORGE, Ighor Rafael de. A base normativa da política de assistência farmacêutica: os efeitos da atividade normativa infralegal. In: BUCCI, Maria Paula Dallari; DUARTE, Clarice Seixas (Coords.). Judicialização da saúde: a visão do poder executivo. São Paulo: Saraiva, 2017, p. 457 - 485.

LAMARÃO NETO, Homero. Judicialização da saúde: o indivíduo e a sociedade de cooperação. Rio de Janeiro: Lumen Juris, 2018.

LAMARÃO NETO, Homero. A regra de solidariedade dos entes federados na área da saúde e sua atual interpretação pelo Supremo Tribunal Federal. Cadernos Ibero-Americanos de Direito Sanitário, v. 8, n. 3, 2019. Disponível em: https://www.cadernos.prodisa.fiocruz.br/index.php/cadernos/article/view/569.

ORGANIZAÇÃO PAN-AMERICANA DA SAÚDE (OPAS). Folha informativa COVID-19 (doença causada pelo novo coronavírus) (Atualizada até 03 de maio de 2020). Disponível em:

https://www.paho.org/bra/index.php?option=com_content\&view=article\&id=6101 :covid19\&Itemid=875. Acesso em: 05 maio 2020.

PARÁ. Procuradoria-Geral do Estado. Cartilha Farmajus: Assistência Farmacêutica no Sus. 2018. Disponível em:

http://www.pge.pa.gov.br/sites/default/files/manuais/cartilha_farmajus_27.12.201 8a.pdf. Acesso em: 18 maio 2020. 
SARLET, Ingo Wolfgang. A eficácia dos direitos fundamentais: uma teoria geral dos direitos fundamentais na perspectiva constitucional. 12. ed. rev. atual e ampl. Porto Alegre: Livraria do advogado editora, 2015.

SARLET, Ingo Wolfgang; MARINONI, Luiz Guilherme; MITIDIERO, Daniel.

Curso de direito constitucional. 8. ed. São Paulo: Saraiva Educação, 2019.

SILVA, Regina Célia dos Santos. Medicamentos excepcionais no âmbito da assistência farmacêutica no Brasil [dissertação]. Rio de Janeiro: Escola Nacional de Saúde Pública Sergio Arouca, Fundação Oswaldo Cruz; 2000. Disponível em: https://www.arca.fiocruz.br/bitstream/icict/5127/2/192.pdf. Acesso em: 04 maio 2020. 